\title{
Effects of therapeutic horse- riding program on the walking ability of students with intellectual disabilities
}

\author{
Ok-Deuk Kang* \\ Animal Biotechnology, Jeju National University, Jeju 63243, Korea
}

Received: Aug 13, 2020

Revised: Oct 14, 2020

Accepted: Nov 19, 2020

*Corresponding author

Ok-Deuk Kang

Animal Biotechnology, Jeju National

University, Jeju 63243, Korea.

Tel: +82-64-727-7005

E-mail: kod0816@gmail.com

Copyright $\odot 2021$ Korean Society of

Animal Sciences and Technology.

This is an Open Access article

distributed under the terms of the

Creative Commons Attribution

Non-Commercial License (http:// creativecommons.org/licenses/bync/4.0/) which permits unrestricted non-commercial use, distribution, and reproduction in any medium, provided the original work is properly cited.

ORCID

Ok-Deuk Kang

https://orcid.org/0000-0003-2231-8581

Competing interests

No potential conflict of interest relevant to this article was reported.

\section{Funding sources}

This work was supported by the Korea Institute of Planning and Evaluation for Technology in Food, Agriculture, and Forestry (Grant No: 316026-02).

\section{Acknowledgements}

Author would like to thankful to the participants and their parents, to the volunteers, and to the physical therapists.

Availability of data and material Upon reasonable request, the datasets of this study can be available from the

\section{Abstract}

The purpose of this study was to determine if an 8-week therapeutic riding (TR) program was effective in improving the walking ability of students with intellectual disabilities. Thirteen students diagnosed with intellectual disabilities participated in the TR program. TR sessions were conducted twice a week (30 min per session), with a total of 16 rides taking place over an 8-week period. A gait measurement analyzer was used to measure progress based on a turn test (6-m walking and turning test), walk test (10-m walking), and timed up and go (TUG) test. Measurements were made three times: before horse-riding (P0), after 4 weeks (8 rides) of horse-riding (P1), and after 8 weeks (16 rides) of horse-riding (P2). Data analysis was conducted using SPSS software (ver. 22.0). Descriptive statistics were generated on the general characteristics of the subjects, and the Kolmogorov-Smirnov test was used to verify the normality of the data. Because of the lack of normality, the data were analyzed using a nonparametric method and the significance level was set to 0.05 . Measurements of the duration of the forward gait cycle $(\mathrm{s})$ in the turn test and the forward gait speed $(\mathrm{m} / \mathrm{s})$ in the walk test indicated improved walking ability after the TR program $(p<0.001)$; the stride length $(\%$ height) also increased significantly $(p<0.05)$. The walk test revealed a significant effect of the program on the duration of the forward gait cycle $(p<0.05)$, while there were significant improvements on the left and right of the elaborated strides $(p<0.001)$. No significant improvement in TUG test performance was observed after the TR program. In this study, an 8-week TR program had positive results on gait. Therefore, further research is merited, where TR programs are likely to improve the walking ability of individuals with intellectual disabilities. Keywords: Gait ability, Intellectual disability, Therapeutic horse-riding, Timed up and go (TUG) test, Turn test, Walk test

\section{INTRODUCTION}

For most humans, walking, as the basic form of locomotion, is the most important activity in everyday life. Gait refers to the way in which the movements of the trunk, legs, pelvis, arms, and head are coordinated to provide forward propulsion. Good joint mobility and body stability are required for effective movement. The body moves while balance and stability are maintained through coordination 
corresponding author.

Authors' contributions

The article is prepared by a single author.

Ethics approval and consent to participate This study protocol was approved by the Institutional Review Board of the Korean National Institute for Bioethics Policy (No. P01-201706-13-001), Korea. of the head, body core, and arms [1].

In general, normal development is delayed in people with intellectual disabilities, often in association with mental or physical disabilities. This limit learning capacity, mobility, and independent daily living [2]. In addition, people with intellectual disabilities may have problems with basic movements such as walking, running, running, and throwing due to inconsistent body segment movements and delayed motion coordination with sensory organs [3]. This limitation of exercise performance can lead to mental problems such as alienation and negative self-concept as well as physical development, and its importance is being emphasized [4]. Walking and balance ability are very closely related [5]. Balance ability is essential for activities of daily living, and refers to the ability to adjust one's balance to maintain the posture when moving the body [6]. When balance ability is insufficient, quality of life deteriorates due to body instability [7]. In particular, people with disabilities may have an asymmetric weight distribution due to their significantly poorer motor skills compared to the general population. Asymmetrical balance causes problems with postural control when performing functional movements, thus impairing walking ability [8]. The impaired physical movements of intellectually disabled people may also predispose them to cardiovascular disease, as well as preventing them from undertaking exercise due to impaired static and dynamic balance, or limitations in physical strength [9].

According to one study [10], the pelvis, which is of central importance for lower extremity functional control, greatly influences the gait pattern, while upper extremity function influences the weight distribution and lateral rotational force of the pelvis. Core muscle exercises are therefore very important to improve the walking ability of people with intellectual disabilities. Horse-riding requires harmonization between the human rider and the horse [11], and can be very beneficial for improving static and dynamic balance $[12,13]$. Horse-riding improves the posture of the trunk and pelvis of the rider, because trunk and pelvic muscle use increases during riding [14-16]. In addition, body stability is improved during horse-riding via continuous stimulation of the vestibular and proprioceptive systems $[14,17,18]$. Uchiyama et al. [19] proved that the body movement of the rider during horse-riding is beneficial for improving posture control ability because it involves more muscle activity than the use of trunk muscle in normal walking.

With the recent increase in horse-riding in Korea, several studies have been conducted to determine the efficacy of riding as a form of physical rehabilitation [20-23]. Various studies have been conducted involving intellectually disabled people. However, those studies were concerned with the large muscles [20], body composition and catecholamines [23], balance ability [24], social function improvement [25], social adaptability [26], and foot pressure and static balance [27].

Most previous studies of gait, including investigations of dynamic and static balance $[12,13]$ and increased activity of trunk and pelvic muscles [14-16], have been conducted in children with cerebral palsy. Walking is associated with a short stride length with minimal ankle involvement; the weight moves forward, which can cause problems with respect to maintaining balance $[28,29]$. Although walking is a very important ability for people with intellectual disabilities, there has been limited research in this area. Therefore, this study investigated the effects of an 8-week therapeutic riding (TR) program on walking ability in intellectually disabled people.

\section{MATERIALS AND METHODS}

\section{Participants}

The study participants were 17 students with intellectual disabilities attending two middle schools. Subjects were students without horseback riding experience. Two of the participants had autism as a comorbid disability, and they did horseback riding but refused to measure it. The other two didn't 
want to ride on the horse and wanted time with the horse. After obtaining the consent of their parents, they helped clean the stables, but did not ride. Therefore, 13 participants were measured and analyzed, and the general characteristics of participants are shown in Table 1. The criterion for study inclusion was the ability to follow the instructions. Students considered at risk in terms of personal safety were excluded. Students were only invited to participate after the study had been explained sufficiently to their parents, and after signed informed consent had been provided for horse-riding and use of data.

\section{Experimental design}

There were two TR sessions per week (total of 8 weeks and 16 rides). The sessions lasted for $30 \mathrm{~min}$ (5 min warm-up exercise, 20 min main exercise, 5 min cool down exercise).

The program (Table 2) used in this study was applied in accordance with a manual published by the Korean Society for Horse Racing (KRA) and a lesson plan book [30]. For students who had difficulty with the program, a lecture was provided according to the individual's disability.

The program instructor was registered with the Professional Association of Therapeutic Horsemanship International (PATH Intl.). Volunteers led the horse, and two walkers assisted the

Table 1. Participants

\begin{tabular}{ccccc}
\hline Diagnosis & Participants & Age & Weight (kg) & Height (cm) \\
\hline Intellectual disability & 13 & $14.60 \pm 1.56$ & $49.31 \pm 9.78$ & $155.80 \pm 10.83$ \\
\hline
\end{tabular}

Table 2. Therapeutic riding program for Intellectual Disabilities

\begin{tabular}{|c|c|}
\hline Time & Lesson content \\
\hline \multirow[t]{2}{*}{1} & -1st evaluation/ understanding of horses \\
\hline & - Communication with horses/mounting and dismounting \\
\hline $2-3$ & - Basic posture of horseback riding \\
\hline \multirow[t]{3}{*}{$4-5$} & - Sense of bridle connection / start and stop sign \\
\hline & - Left and right direction adjustment in walk \\
\hline & - Learn the rhythm of walk \\
\hline \multirow[t]{3}{*}{$6-7$} & - Correct riding posture of walk and trot \\
\hline & - Learn how to control and drive a horse \\
\hline & - Learn how to rising trot \\
\hline \multirow[t]{3}{*}{8} & - Rider's posture in walk and trot \\
\hline & - Getting the right reins, rising trot rhythm \\
\hline & -2nd evaluation \\
\hline \multirow[t]{2}{*}{$9-10$} & - walk and sitting rhythm/ correct riding posture \\
\hline & - Learn how to control, rising trot rhythm \\
\hline \multirow[t]{2}{*}{$11-12$} & - Circling (rotation), rising trot rhythm \\
\hline & - Half Seat (2-point up), balance, use the rein and weight \\
\hline \multirow[t]{3}{*}{$13-14$} & - Use the rein and weight \\
\hline & - Weight shift to rotate circles \\
\hline & • Half seat (2-point up), balance \\
\hline \multirow[t]{4}{*}{$15-16$} & • Half seat (2-point up), balance \\
\hline & - Playing cavaletti (learning speed and left-hand rebound) \\
\hline & - Direction change and rein adjustment method \\
\hline & -3rd evaluation \\
\hline
\end{tabular}


rider (one on each side of the horse). After each lesson, time was provided for discussion among between the participants, their guardians, the volunteers, instructors, and horse-riding officials. This aim was to ensure that the participants could ride in a comfortable atmosphere. Measurements were made before riding began (P0), and after 4 weeks (8 rides) ( $\mathrm{P} 1)$, and 8 weeks (16 rides) (P2).

\section{Gait analysis}

Gait analysis is to analyze periodically repeated gait in a certain pattern. Normal walking refers to repeated movements of the lower limbs that move the body while maintaining upright stability [31]. Walking starts from the heel, and after the heel of the opposite foot touches the ground, it means until the same heel touches the ground again. These two step movements are called strides and become one cycle of the walking cycle. In general, the gait analysis verifies the walking speed and step size after walking a distance of about $10 \mathrm{~m}$. In this study, the Turn test, $10 \mathrm{~m}$ walking test, and Timed Up \& Go (TUG) Test, which are commonly used for gait analysis, were used for gait analysis of the subject.

\section{Tools for measurement}

A highly reliable wearable gait measurement analyzer (G-Walk, BTS Bioengineering, Milano, Italy) was used in this study (intra class correlation coefficient [ICC] = $0.84-0.99$ [32]) (Fig. 1). Using a wireless 3-axis accelerometer, the spatiotemporal walking data were transmitted to a computer via a Bluetooth system and analyzed using BTS G-Studio software (BTS Bioengineering, Milano). There are three variables used: Turn Test, Walk, and TUG, and the sub-items are shown in Table 3 and Fig. 2. Data was measured by a professional occupational therapist, and the analysis results were analyzed by a rehabilitation expert. Data was measured by a professional occupational therapist, and the analysis results were analyzed by a rehabilitation expert.

\section{Turn test (6-m walking test)}

The turn test measured the maximum walking speed when walking through a flat 6-m section of indoor corridor, turning, and returning to the start position (Table 3 and Fig. 2A).

\section{Walk test (10-m walking test)}

The 10-m walk test measured the time taken to walk through a flat 10-m indoor corridor. This test can be used to measure walking performance and recovery, and has a high level of intra-and intermeasurement reliability $(r=0.95-0.96)$ [33]. Walk test are shown in Table 3 and Fig. 2B.
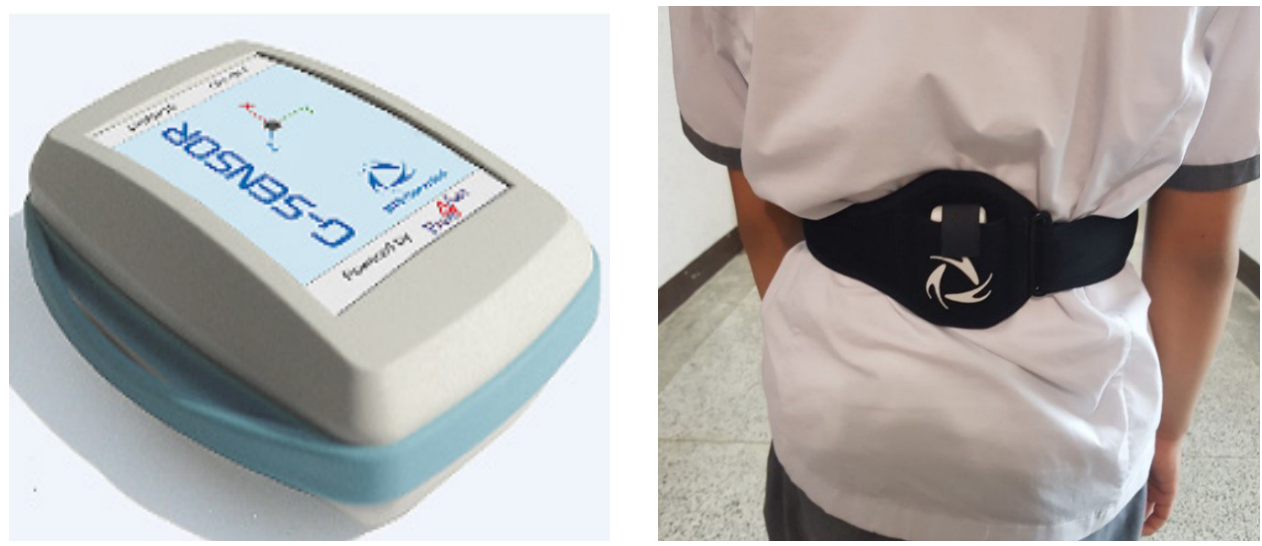

Fig. 1. Measurement equipment. 
(A)

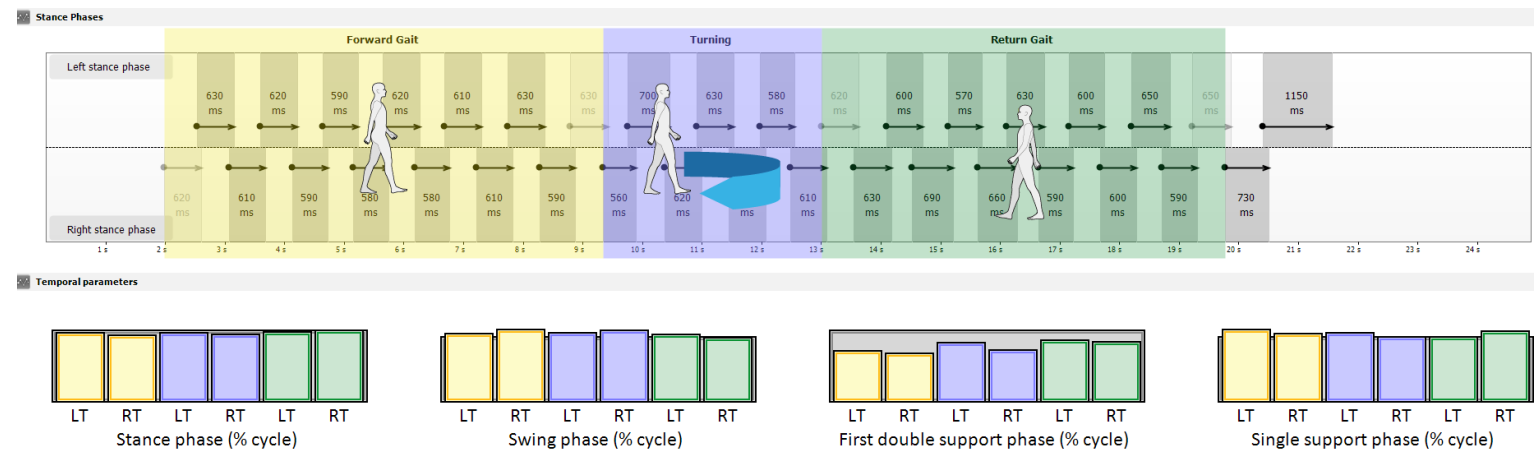

(B)

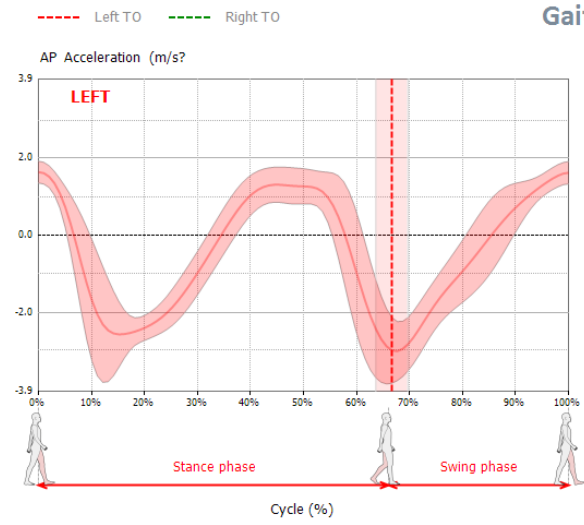

Gait Cycle

Symmetry Index: 99.0

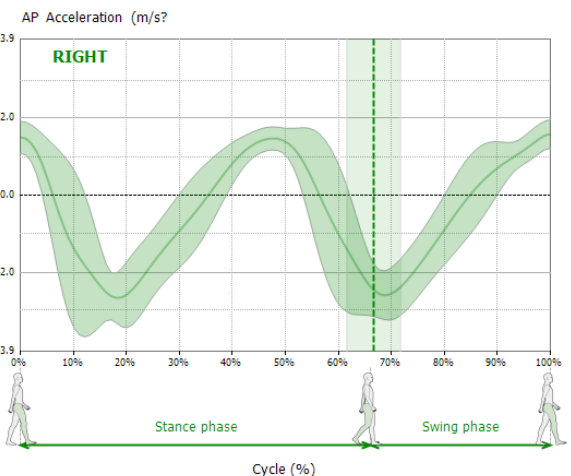

(C)

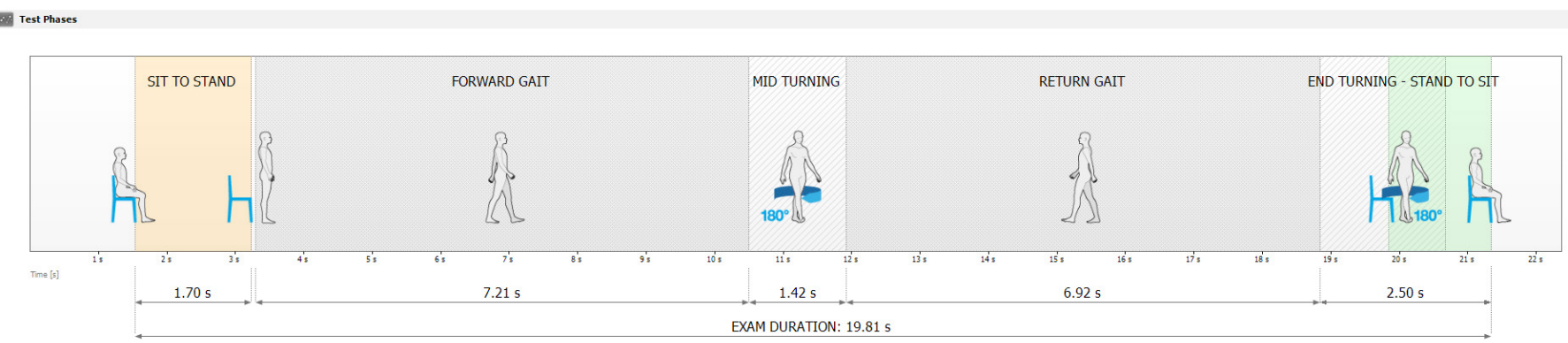

Fig. 2. (A) Turn test, (B) Walk test, (C) TUG. TUG, timed up and go; LT, left; RT, right.

\section{Timed up and go (TUG) test}

A series of TUG tests were conducted to measure the functional mobility and gait ability of the participants. Each subject sat in a chair and waited for the evaluator to say the word "departure", at which point they rose from the chair, walked $3 \mathrm{~m}$, and then returned to sit on the chair again. The time taken between rising from and sitting back down on the chair was recorded.

The test-retest reliability coefficient for the TUG test has a high level of intra-measurement $(r$ $=0.99)$ and inter-measurement reliability $(r=0.098)$ [34]. The TUG test has been used to estimate balance ability and predict the risk of falling [35]. The TUG test has seven domains: total time taken, sit-to-stand, forward gait, mid-turning, return gait, end-turning, and stand-to-sit (Table 3 and Fig. 2C). 


\begin{tabular}{|c|c|c|c|c|}
\hline \multirow[t]{6}{*}{ Turn Test } & Analysis duration (s) & Forward gait & Turning & Return gait \\
\hline & Speed $(\mathrm{m} / \mathrm{s})$ & & & \\
\hline & Cadence (steps/min) & & & \\
\hline & $\%$ Stride length $(\mathrm{m} / \mathrm{s})$ & & & \\
\hline & Stride length $(m)$ & & & \\
\hline & Gait cycle duration (s) & & & \\
\hline \multirow[t]{11}{*}{ Walk } & Analysis duration (s) & & & \\
\hline & Cadence (steps/min) & & & \\
\hline & Speed $(\mathrm{m} / \mathrm{s})$ & & & \\
\hline & Stride length (m) & & & \\
\hline & Stride length \% (\%height) & & & \\
\hline & Gait cycle duration (s) & & Left & Right \\
\hline & Step length (\%Stride length) & & & \\
\hline & Stance phase (\%cycle) & & & \\
\hline & First double support phase (\%cycle) & & & \\
\hline & Single support phase (\%cycle) & & & \\
\hline & Stance phase (\%cycle) & & & \\
\hline \multirow[t]{8}{*}{ TUG } & Analysis duration (s) & & & \\
\hline & Phase duration (s) & & Sit to stand & Stand to sit \\
\hline & Antero-posterior acceleration $\left(\mathrm{m} / \mathrm{s}^{2}\right)$ & & & \\
\hline & Lateral acceleration $\left(\mathrm{m} / \mathrm{s}^{2}\right)$ & & & \\
\hline & Vertical acceleration $\left(\mathrm{m} / \mathrm{s}^{2}\right)$ & & & \\
\hline & Phase duration (s) & & & \\
\hline & Maximum rotation speed $(\% / s)$ & & & \\
\hline & Average rotation speed $(\% / s)$ & & & \\
\hline
\end{tabular}

TUG, timed up and go.

\section{Data analysis}

The data were analyzed using SPSS software (ver. 22.0; SPSS, Chicago, IL, USA). Data were analyzed using a one-way repeated analysis of variance (ANOVA). Descriptive statistics were generated on the general characteristics of the participants, and the Kolmogorov-Smirnov test was used to verify the normality of the data. The significance level was set to 0.05 .

\section{RESULTS}

The normality test indicated a non-normal distribution of the data, so a nonparametric method was used for the analysis. The results for the turn test, walk, and TUG test is shown in Tables 3, 4, and 5 .

\section{Turn test results}

The results of the turn test (6-m walking test) are presented in Table 4. The duration of the forward gait cycle was significantly different between $\mathrm{P} 2(4.9 \pm 1.2 \mathrm{~s})$ and $\mathrm{P} 0(6.8 \pm 2.2 \mathrm{~s})(p<0.001)$. There was no difference in duration between the turning and return gait components. The forward gait speed $(\mathrm{m} / \mathrm{s})$ was significantly higher in P2 $(1.5 \pm 0.3 \mathrm{~m} / \mathrm{s})$ compared to P0 $(1.3 \pm 0.3 \mathrm{~m} / \mathrm{s})(p$ $<0.001)$, and turning gait speed increased in $\mathrm{P} 2(1.5 \pm 0.6 \mathrm{~m} / \mathrm{s})$ compared to $\mathrm{P} 0(1.3 \pm 0.3 \mathrm{~m} / \mathrm{s})$. Return gait speed increased in P2 $(1.5 \pm 0.4 \mathrm{~m} / \mathrm{s})$ compared to $\mathrm{P} 0(1.4 \pm 0.4 \mathrm{~m} / \mathrm{s})$, but there was no significant difference. The forward gait speed and cadence (steps/min) increased after completing 
Table 4. Change of turn test before and after TR program in students with intellectual disabilities

\begin{tabular}{|c|c|c|c|c|}
\hline Parameters & PO & P1 & P2 & $p$-vaule \\
\hline \multicolumn{5}{|l|}{ Analysis duration (s) } \\
\hline Forward gait & $6.8^{\mathrm{a}} \pm 2.2$ & $5.8^{\mathrm{a}, \mathrm{b}} \pm 1.0$ & $4.9^{b} \pm 1.2$ & 0.001 \\
\hline Turning & $4.3 \pm 1.5$ & $4.0 \pm 0.9$ & $4.6 \pm 1.8$ & 0.735 \\
\hline Return gait & $5.2 \pm 2.0$ & $5.0 \pm 0.9$ & $3.9 \pm 1.4$ & 0.070 \\
\hline \multicolumn{5}{|l|}{ Speed $(\mathrm{m} / \mathrm{s})$} \\
\hline Forward gait & $1.3^{\mathrm{b}} \pm 0.3$ & $1.4^{\mathrm{a}, \mathrm{b}} \pm 0.2$ & $1.5^{\mathrm{a}} \pm 0.3$ & 0.006 \\
\hline Turning & $1.3 \pm 0.3$ & $1.7 \pm 1.0$ & $1.5 \pm 0.6$ & 0.125 \\
\hline Return gait & $1.4 \pm 0.4$ & $1.6 \pm 0.7$ & $1.5 \pm 0.4$ & 0.297 \\
\hline \multicolumn{5}{|l|}{ Cadence (steps/min) } \\
\hline Forward gait & $119.4 \pm 12.4$ & $115.7 \pm 13.0$ & $120.8 \pm 16.2$ & 0.150 \\
\hline Turning & $115.0 \pm 15.3$ & $112.8 \pm 17.4$ & $115.5 \pm 8.7$ & 1.000 \\
\hline Return gait & $123.1 \pm 18.4$ & $119.1 \pm 11.3$ & $119.4 \pm 10.6$ & 0.529 \\
\hline \multicolumn{5}{|l|}{$\%$ Stride length $(\mathrm{m} / \mathrm{s})$} \\
\hline Forward gait & $86.5 \pm 13.8$ & $90.9 \pm 11.5$ & $90.0 \pm 18.1$ & 0.078 \\
\hline Turning & $83.9 \pm 15.3$ & $91.2 \pm 15.4$ & $89.0 \pm 14.1$ & 0.046 \\
\hline Return gait & $91.1 \pm 17.0$ & $88.0 \pm 15.0$ & $92.3 \pm 17.6$ & 0.695 \\
\hline \multicolumn{5}{|l|}{ Stride length (m) } \\
\hline Forward gait & $1.3 \pm 0.2$ & $1.4 \pm 0.2$ & $1.4 \pm 0.3$ & 0.052 \\
\hline Turning & $1.3 \pm 0.2$ & $1.5 \pm 0.5$ & $1.4 \pm 0.3$ & 0.058 \\
\hline Return gait & $1.4 \pm 0.3$ & $1.4 \pm 0.2$ & $1.4 \pm 0.3$ & 0.643 \\
\hline \multicolumn{5}{|l|}{ Gait cycle duration (s) } \\
\hline Forward gait & $1.0 \pm 0.1$ & $1.0 \pm 0.1$ & $1.0 \pm 0.1$ & 0.245 \\
\hline Turning & $1.0 \pm 0.3$ & $1.0 \pm 0.1$ & $1.0 \pm 0.1$ & 0.551 \\
\hline Return gait & $1.0 \pm 0.1$ & $1.0 \pm 0.1$ & $1.0 \pm 0.1$ & 0.358 \\
\hline
\end{tabular}

$\overline{a, b}$ Means with different superscripts significantly differ $(p<0.05)$.

$T R$, therapeutic riding.

the TR program, but not significantly, while the return gait speed was lower in $\mathrm{P} 2$ compared to $\mathrm{P} 0$. Stride length was significantly longer in $\mathrm{P} 2(89.0 \pm 14.1 \%$ of height) compared to $\mathrm{P} 0(83.9 \pm 15.3 \%$ of height, $p<0.05)$. There was no significant difference in stride length or gait cycle duration after the TR program.

\section{Walk test results}

The results of the walk test (10-m walking test) are presented in Table 5. The analysis duration results for $\mathrm{P} 0, \mathrm{P} 1$, and $\mathrm{P} 2$ were significantly decreased $42.6 \pm 8.1,43.3 \pm 7.1$, and $37.6 \pm 7.4 \mathrm{~s}$, respectively $(p<0.05)$. The elaborated stride (\% cycle) values for $\mathrm{P} 0$, $\mathrm{P} 1$, and $\mathrm{P} 2$ were $25.4 \pm 5.5$, $27.5 \pm 6.1$, and $21.6 \pm 4.7$, respectively $(p<0.001)$. The right mean values were $25.3 \pm 5.0,27.8 \pm 5.9$, and $21.9 \pm 4.5 \mathrm{~s}$, respectively.

\section{TUG test results}

The results of the TUG test are presented in Table 6. The duration of the sit-to-stand phase for P0 and $\mathrm{P} 2$ was $1.3 \pm 0.3$ and $1.4 \pm 0.2 \mathrm{~s}$, respectively, while the values for the stand-to-sit phase were $1.8 \pm 2.2$ and $1.4 \pm 0.6 \mathrm{~s}$, respectively. The sit-to-stand phase antero-posterior acceleration was 6.0 \pm 2.6 and $5.1 \pm 1.7 \mathrm{~m} / \mathrm{s}^{2}$ for $\mathrm{P} 0$ and $\mathrm{P} 2$, respectively, while in the stand-to-sit phase it increased to $8.3 \pm 5.3$ and $6.3 \pm 4.2 \mathrm{~m} / \mathrm{s}^{2}$, respectively. However, the difference was not significant. The sit-to- 
Table 5. Change of walk test before and after TR program in students with intellectual disabilities

\begin{tabular}{|c|c|c|c|c|}
\hline Parameters & Po & P1 & P2 & $p$-vaule \\
\hline Analysis duration (s) & $42.6^{a} \pm 8.1$ & $43.3^{\mathrm{a}, \mathrm{b}} \pm 7.1$ & $37.6^{\mathrm{b}} \pm 7.4$ & 0.023 \\
\hline Cadence (steps/min) & $124.3 \pm 13.5$ & $123.6 \pm 10.4$ & $125.2 \pm 14.4$ & 0.926 \\
\hline Speed $(\mathrm{m} / \mathrm{s})$ & $0.7 \pm 0.3$ & $0.7 \pm 0.3$ & $0.7 \pm 0.2$ & 0.545 \\
\hline Stride length $(m)$ & $0.7 \pm 0.3$ & $0.7 \pm 0.3$ & $0.7 \pm 0.1$ & 0.926 \\
\hline Stride length \% (\%height) & $39.3 \pm 22.0$ & $38.8 \pm 21.6$ & $42.7 \pm 12.6$ & 0.735 \\
\hline \multicolumn{5}{|l|}{ Gait cycle duration (s) } \\
\hline Left & $1.0 \pm 0.1$ & $1.0 \pm 0.1$ & $1.0 \pm 0.1$ & 0.869 \\
\hline Right & $1.0 \pm 0.1$ & $1.0 \pm 0.1$ & $1.0 \pm 0.1$ & 0.832 \\
\hline \multicolumn{5}{|l|}{ Step length (\%stride length) } \\
\hline Left & $49.8 \pm 1.2$ & $54.9 \pm 16.8$ & $46.7 \pm 12.7$ & 0.584 \\
\hline Right & $50.3 \pm 1.1$ & $50.2 \pm 1.7$ & $50.4 \pm 2.7$ & 0.913 \\
\hline \multicolumn{5}{|l|}{ Stance phase (\%cycle) } \\
\hline Left & $67.7 \pm 3.1$ & $67.7 \pm 4.7$ & $66.0 \pm 4.7$ & 0.353 \\
\hline Right & $67.4 \pm 2.7$ & $66.9 \pm 4.6$ & $66.0 \pm 4.1$ & 0.383 \\
\hline \multicolumn{5}{|l|}{ Swing phase (\%cycle) } \\
\hline Left & $32.6 \pm 3.2$ & $32.8 \pm 4.9$ & $34.1 \pm 4.5$ & 0.589 \\
\hline Right & $32.6 \pm 2.7$ & $33.1 \pm 4.6$ & $34.0 \pm 4.1$ & 0.383 \\
\hline \multicolumn{5}{|c|}{ First double support phase (\%cycle) } \\
\hline Left & $17.3 \pm 3.0$ & $17.0 \pm 5.0$ & $15.9 \pm 4.3$ & 0.584 \\
\hline Right & $17.3 \pm 2.9$ & $16.9 \pm 4.5$ & $15.9 \pm 3.9$ & 0.199 \\
\hline \multicolumn{5}{|c|}{ Single support phase (\%cycle) } \\
\hline Left & $32.7 \pm 2.8$ & $33.2 \pm 4.6$ & $34.1 \pm 4.2$ & 0.232 \\
\hline Right & $32.5 \pm 3.1$ & $32.8 \pm 4.8$ & $34.1 \pm 4.3$ & 0.589 \\
\hline \multicolumn{5}{|l|}{ Elaborated strides (\%cycle) } \\
\hline Left & $25.4^{\mathrm{a}} \pm 5.5$ & $27.5^{\mathrm{a}} \pm 6.1$ & $21.6^{\mathrm{b}} \pm 4.7$ & 0.001 \\
\hline Right & $25.3^{\mathrm{a}, \mathrm{b}} \pm 5.0$ & $27.8^{\mathrm{a}} \pm 5.9$ & $21.9^{b} \pm 4.5$ & 0.000 \\
\hline
\end{tabular}

${ }^{a, b}$ Means with different superscripts significantly differ $(p<0.05)$.

$T R$, therapeutic riding.

Table 6. Change of TUG before and after TR program in students with intellectual disabilities

\begin{tabular}{llrrrc}
\hline \multicolumn{1}{c}{ Parameters } & & P0 & P1 & P2 & p-vaule \\
\hline Analysis duration $(\mathrm{s})$ & & $18.7 \pm 2.5$ & $19.2 \pm 4.2$ & $17.1 \pm 2.2$ & 0.118 \\
Phase duration $(\mathrm{s})$ & Sit to stand & $1.3 \pm 0.3$ & $1.4 \pm 0.2$ & $1.4 \pm 0.2$ & 0.978 \\
& Stand to sit & $1.8 \pm 2.2$ & $2.5 \pm 3.0$ & $1.4 \pm 0.6$ & 0.291 \\
Antero-posterior & Sit to stand & $6.0 \pm 2.6$ & $5.1 \pm 1.7$ & $5.1 \pm 1.7$ & 0.656 \\
acceleration $\left(\mathrm{m} / \mathrm{s}^{2}\right)$ & Stand to sit & $8.3 \pm 5.3$ & $7.4 \pm 4.5$ & $6.3 \pm 4.2$ & 0.500 \\
Lateral acceleration $\left(\mathrm{m} / \mathrm{s}^{2}\right)$ & Sit to stand & $4.1 \pm 1.9$ & $4.2 \pm 1.1$ & $4.5 \pm 2.8$ & 1.000 \\
& Stand to sit & $5.0 \pm 2.4$ & $5.9 \pm 4.2$ & $5.0 \pm 2.6$ & 0.657 \\
Vertical acceleration $\left(\mathrm{m} / \mathrm{s}^{2}\right)$ & Sit to stand & $7.5 \pm 2.0$ & $7.3 \pm 2.8$ & $6.8 \pm 2.6$ & 0.558 \\
& Stand to sit & $11.9 \pm 6.9$ & $11.3 \pm 6.0$ & $9.3 \pm 6.4$ & 0.232 \\
Phase duration $(\mathrm{s})$ & Sit to stand & $1.4 \pm 0.6$ & $1.3 \pm 0.8$ & $1.9 \pm 0.8$ & 0.057 \\
& Stand to sit & $1.1 \pm 0.8$ & $1.1 \pm 0.5$ & $1.3 \pm 0.6$ & 0.767 \\
Maximum rotation speed $(\% / \mathrm{s})$ & Sit to stand & $139.1 \pm 43.7$ & $145.2 \pm 50.2$ & $143.0 \pm 38.7$ & 0.779 \\
& Stand to sit & $166.2 \pm 60.2$ & $193.7 \pm 44.4$ & $185.6 \pm 40.6$ & 0.529 \\
Average rotation speed $(\% / \mathrm{s})$ & Sit to stand & $75.0 \pm 20.0$ & $80.4 \pm 22.9$ & $70.0 \pm 21.4$ & 0.307 \\
& Stand to sit & $89.4 \pm 34.9$ & $101.5 \pm 31.5$ & $97.5 \pm 31.8$ & 0.761 \\
\hline
\end{tabular}

TUG, timed up and go; TR, therapeutic riding. 
stand lateral acceleration increased from $4.1 \pm 1.9 \mathrm{~m} / \mathrm{s}^{2}$ for $\mathrm{P} 0$ to $4.5 \pm 2.8 \mathrm{~m} / \mathrm{s}^{2}$ for P1, while in the stand-to-sit phase it remained almost constant, at $5.0 \pm 2.4 \mathrm{~m} / \mathrm{s}^{2}$ for P0 and $5.0 \pm 2.6 \mathrm{~m} / \mathrm{s}^{2}$ for P1 . The sit-to-stand vertical acceleration decreased from $7.5 \pm 2.0 \mathrm{~m} / \mathrm{s}^{2}$ for P0 to $6.8 \pm 2.6 \mathrm{~m} / \mathrm{s}^{2}$ for P2, while in the stand-to-sit phase it decreased from $11.9 \pm 6.9 \mathrm{~m} / \mathrm{s}^{2}$ for P0 to $9.3 \pm 6.4 \mathrm{~m} / \mathrm{s}^{2}$ for P2. No significant differences were found for any of the parameters measured in the TUG test after the PR program.

\section{DISCUSSION}

The purpose of this study was to investigate the effects of 16 sessions of a TR program on the gait characteristics of students with intellectual disabilities. After the 8-week (16 rides) TR program, the gait of the subjects was confirmed to have improved. Walking is an essential ability for daily life activities. Most people with intellectual disabilities have difficulty with exercise, and must manage various problems [36]. People with intellectual disabilities tent to have low levels of physical fitness due to delayed functional development [37]. Many studies have been conducted to determine how to improve the walking ability [38-41].

For gait evaluation, Hwang et al. [38] used the 10-m walking speed, TUG test, and 6-min walking test. Kim et al. [42] used a 10-min walking test and the TUG test, and Song [41] used 6-m, 10-m, and 3-m (backward) walking tests, together with an evaluation of stair-climbing and -descending ability. In this study, a turn test (6-m walking and turning test), walk test (10-m walking), and TUG test were used. In the turn test, the duration of the forward gait cycle (s) was significantly decreased after the TR program $(p<0.001)$, while the forward gait walking speed $(\mathrm{m} /$ s) was significantly increased $(p<0.05)$.

The decreased duration of the forward gait cycle indicates that walking speed increased. Gait speed, as a measure of gait ability, is useful for evaluating the performance of physically disabled people [39].

In the $10-\mathrm{m}$ walking test, elaborated strides (\% cycle) in both the left $(p<0.001)$ and the right $(p$ $<0.001)$ significantly decreased, indicating a positive effect of the TR program. In the TUG test, the duration of the stand-to-sit phase (s) decreased after the TR program, but not significantly. Both the sit-to-stand and stand-to-sit maximum rotation speeds $(\mathrm{m} / \mathrm{s})$ increased, but not significantly.

Hwang et al. [38] reported very positive outcomes of a gait training program emphasizing social aspects for stroke patients. Lim and Kim [39] reported a significant improvement in gait after 12 weeks of strength, balance, and gait training in children with Down syndrome. In addition, Son et al. [41] reported an improvement in gait ability after a 12-week strength, balance and gait training program for intellectually and hearing-impaired people. Based on the results of these previous studies, it was expected that strength, balance, and walking training would have a stabilizing effect on posture by improving lower extremity strength; our findings support the previous studies. Although the type of disability differed among the studies, walking ability always refers to movement of the trunk, legs, pelvis, arms, and head, and is affected by balance and stability [1]. Balance is a very important component of the posture and movement required for activities of daily living [43]. When a person moves their body, balance is needed to control and maintain the posture [6]. This construct can be applied to people with a range of disabilities. Many researchers have aimed to improve the balance of people with disabilities.

TR has proven to be an effective exercise method for disabled populations; it promotes balance [12,13], symmetrical posture of the trunk and pelvis [14-16], and stability of the body via continuous stimulation of the vestibular and proprioceptive systems [14,17-18].

Exercises aimed at maintaining balance while moving on an unstable support surface are very 
effective for improving balance [44]. During horse-riding, forward, stopping, and turning postures and movements are used to guide the horse in the desired direction, and shifting the body weight is essential in this process. Horse-riding emphasizes coordination, and two or three assistants can provide a means of communication with the horse. For example, to move to the left, it is common to pull the reins and convey various signals to the horse at the same time (e.g., eye movements).

As the riding progresses, the balance of the rider will be improved by integration of sensory stimulation. The improvement in balance should eventually improve walking ability.

Unfortunately, the TUG test in our study did not yield satisfactory results. We expected the TR program to lead to very significant improvements in the walking ability of our intellectually disabled students, because the contents of the program were tailored specifically for this population. However, although the TUG test results indicated some improvement, no significant results were obtained. The TUG test can be used to assess muscle strength, walking ability, and endurance of the ankle flexor muscle, which is an important component of walking ability [8].

Park and Choi [24] reported a significant improvement $(p<0.001)$ in TUG test performance following the completion of a horse-riding program for participants with intellectual disabilities. Similarly, Lee et al. [45] reported a significant improvement in TUG test results after horse-riding in elderly women $p<0.001$ ). In addition, Choi and Cho [46] reported a significant improvement in TUG test results for patients with cerebral infarction after using a horse-riding machine $(p<0.05)$. Park and Choi [24] used 36 horse-riding sessions in their study, while Choi and Cho [46] used 18 sessions and Lee et al. [45] 24 sessions. As we used only 16 sessions, our TR program could be considered relatively short.

In the study of Park and Choi [24], the duration of the forward gait cycle in the TUG test improved from $21.07 \pm 0.86 \mathrm{~s}$ before their TR program to $16.34 \pm 1.5 \mathrm{~s}$ thereafter, while in the study of Lee et al. [45] it improved from $20.33 \pm 1.3 \mathrm{~s}$ to $15.05 \pm 0.84 \mathrm{~s}$. Choi and Cho [46] also reported an improvement in walking ability, with a time of $20.41 \pm 6.91 \mathrm{~s}$ before exercise and 17.86 $\pm 6.07 \mathrm{~s}$ after exercise. The average duration of the forward gait cycle among our students with intellectual disabilities in the TUG test was $18.7 \pm 2.5 \mathrm{~s}$ before the program, which was higher than the value of $10 \mathrm{~s}$ or less expected for adults with no disability, but lower than the baseline levels reported in previous studies. This indicates an improvement in walking ability.

Individuals with a TUG test time of more than $16 \mathrm{~s}$ are classified as being at risk of falling [47], while 11 to $20 \mathrm{~s}$ is typical for elderly or disabled persons, and values over $20 \mathrm{~s}$ indicate impaired functional mobility [48]. For individuals with test times longer than $30 \mathrm{~s}$, outdoor activities are impossible due to the inability to walk independently [49]. Although the TUG test results in this study indicated a decrease in duration of the forward gait cycle after the TR program, this was not significant. Nevertheless, the gradual decrease did suggest some improvement. In addition, the results of the turn and 10-m walking tests indicated improved walking ability. Our TR program is a whole-body exercise that not only has physical effects, but also emotional, psychological, and social effects. The most important advantage of the TR program is that the subject can participate in it as if it were a hobby, as opposed to a training program; this makes it an attractive exercise that can produce positive results in a natural manner.

Various sensory enhancements can be expected in the rider through assimilating the rhythmic movements that occur while the horse is walking. These movements have a similarity to those of the human gait of more than $98 \%$. Thus, horse-riding can be recommended as a means to achieve physical [38-41], psychological [15,50], and social improvements [25] in both disabled and non-disabled populations. However, the small sample size of this study may limit the interpretation of the study results. Therefore, it seems that future research on TR programs should be designed to increase the number of subjects. TR is subject to several limitations. Large animal horses must be 
used, access to the riding grounds is not easy, and there are limitations that must be conducted for the disabled. For this reason, it was carried out for a small number of samples. This has limitations in generalizing the effect of TR on gait. In addition, it seems to be necessary to find a way to apply a longer duration of the TR program considering the characteristics of disability. Nevertheless, it is thought that the results of this study can be used as basic data for the gait status of the intellectually disabled through TR.

\section{REFERENCES}

1. Galley PM, Forster AL. Human movement. Philadelphia (PA): Churchill-Livingstone Publications. Melbourne, Australia. 1987.

2. Lee $\mathrm{SH}, \mathrm{Cho} \mathrm{HJ}$. A revies on the concepts of developmental disabilities in special education. J Korean Assoc Dev Disabil. 2001;5:17-30.

3. Hartman E, Houwen S, Scherder E, Visscher C. On the relationship between motor performance and executive functioning in children with intellectual disabilities. J Intellect Disabil Res. 2010;54:468-77.https://doi.org/10.1111/j.1365-2788.2010.01284.x

4. Lee YH, Hong HJ, Joung, HJ. The effects of community dance on motor ability in students with intellectual disabilities: a pilot study. OffJ Korean Soc Dance Sci. 2017;34:1-17.

5. Dite W, Temple VA. A clinical test of stepping and change of direction to identify multiple falling older adults. Arch Phys Med Rehabil. 2002;83:1566-71. https://doi.org/10.1053/ apmr.2002.35469

6. Raymakers JA, Samson MM, Verhaar HJJ. The assessment of body sway and the choice of stability parameter(s). Gait Posture. 2005;21:48-58. https://doi.org/10.1016/ j.gaitpost.2003.11.006

7. Laughton CA, Slavin M, Katdare K, Nolan L, Bean JF, Kerrigan DC, et al. Aging, muscle activity, and balance control: physiologic changes associated with balance impairment. Gait Posture. 2003;18:101-8. https://doi.org/10.1016/S0966-6362(02)00200-X

8. $\mathrm{Ng}$ SS, Chan LH, Chan CS, Lai SH, Wu WW, Tse MM, et al. Parallel walk test: its correlation with balance and motor functions in people with chronic stroke. Arch Phys Med Rehabil. 2015;96:877-84. https://doi.org/10.1016/j.apmr.2014.11.002

9. Draheim CC, Williams DP, McCubbin JA. Prevalence of physical inactivity and recommended physical activity in community-based adults with mental retardation. Ment Retard. 2002;40:436-44. https://doi.org/10.1352/0047-6765(2002)040<0436:POPIAR>2.0.CO;2

10. Moon JK. The effects of pelvic movement on the gross motor function in cerebral palsy children with spastic diplegia. Neurotherapy. 2017;21:57-63.

11. Wuang YP, Wang CC, Huang MH, Su CY. The effectiveness of simulated developmental horse-riding program in children with autism. Adapt Phys Activ Q. 2010;27:113-26. https:// doi.org/10.1123/apaq.27.2.113

12. Han SC, Choo HK, Lee SH. The effects of horseback riding on the balance improvement of the children with cerebral palsy. J Korean Phys Edu. 2004;43:601-10.

13. Jung TW, Cho HG, Park JY, Kim TS. The effects of therapeutic horse riding activities to balance of the children with cerebral palsy. Korean J Adapt Phys Act.2016;24:111-21. https://doi. org/10.1053/apmr.2002.35469

14. Jung JH, Lee BH, Yu JH, Shin JS. The effects of horseback riding on the hand function, visual perception and activities of daily living in children with cerebral palsy. J Rehabil Res. 2010;14:1-22.

15. Jeong SH, Jeong TW, Cho HG. The effects of horse riding activities on equilibrium and back- 
bone posture of the children with cerebral pals. J Adapt Phys Activ. 2011;19:79-90. https://doi. org/10.17006/kjapa.2011.19.2.79

16. Cho SH, Oh BW, Whang BG. The effects of hippotherapy on the activities of trunk muscles in preterm born children with spastic cerebral palsy. J Spec Educ Rehabil Sci. 2012;51:349-64.

17. Eils E, Rosenbaum D. A multi-station proprioceptive exercise program in patients with ankle instability. Med sci sports exerc. 2001;33:1991-8. https://doi.org/10.1097/00005768200112000-00003

18. Olivier A, Faugloire, E, Lejeune L, Biau S, Isableu B. Head stability and head-trunk coordination in horseback riders: the contribution of visual information according to expertise. Hum Neurosci. 2017;30. https://doi.org/10.3389/fnhum.2017.00011

19. Uchiyama $\mathrm{H}$, Ohtani $\mathrm{N}$, Ohta M. Three-dimensional analysis of horse and human gaits in therapeutic riding. Appl Anim Behav Sci. 2011;135:271-6. https://doi.org/10.1016/j.applanim.2011.10.024

20. Park GR, Kwon SJ. An influence of horse riding on gross motor skill development in mentally handicapped students. Korean Soc Sport Sci. 2011;20:1003-9.

21. Kang OD. The effects of horse riding program for developmental delay improvement in children with cerebral palsy.J Spec Educ Rehabil Sci. 2014;53.1-17.

22. Kim JK, Kim HS, Park SJ. The effects of therapeutic horseback riding on postural control and visual perception of children with cerebral palsy.J Korean Health Fund Med Sci. 2017;10:1-5.

23. Lee CS, Lee KH. Effects of therapeutic horse riding on body composition and catecholamines in adolescents with intellectual disabled. J Korean soc Wellness. 2017;12:401-10. https://doi. org/10.21097/ksw.2017.05.12.2.401

24. Park $\mathrm{BH}$, Choi $\mathrm{KH}$. The effect of a therapeutic riding program for rehabilitation on balance and brain wave in people with intellectual disabilities. Korean J Adapt Phys Act. 2016;24:8999.

25. Lee IS, Kang OD. The effects on social adaptability of therapeutic riding in children with intellectual disabilities.J Spec Educ Rehabil Sci. 2014;53:223-34.

26. Kim SK, Lee SW. The effects of the horse riding exercise program for the social adaptability of the children with intellectual disabilities.J Spec Educ Rehabil Sci. 2011;50:83-9.

27. Park JS, Kwak YS, Yang JO. Effects of the upright body type excercise-II on foot pressure and static balance in students with mild intellectual disabilities. J Coaching Devel. 2019;21:118-26. https://doi.org/10.47684/jcd.2019.03.21.1.118

28. Oh SG, Yi JH. A Kinematic analysis on the treadmill gait of children with Down Syndrome.J Korea Acad-Ind Coop Soc. 2011;12:3834-42. https://doi.org/10.5762/KAIS.2011.12.9.3834

29. Jeon H, Kim H, Park J. Validity of self-efficacy theory for transtheoretical model. Korean Assoc Physical Edu Sport for Girls Women. 2010;24:71-80.

30. Kang, OD. Lesson plan for rehabilitation riding lessons. Gyeongbuk, Korea: Daeyoung Publisher. 2017.

31. De Ridder R, Lebleu J, Willems T, De Blaiser C, Detrembleur C, Roosen P. Concurrent validity of a commercial wireless trunk triaxial accelerometer system for gait analysis.J Sport Rehabil. 2019;28:1-4. https://doi.org/10.1123/jsr.2018-0295

32. De Ridder R, Lebleu J, Willems T, et al(2019). Concurrent validity of a commercial wireless trunk triaxial accelerometer system for gait analysis. J Sport Rehabil, 28(6). Printed Online. https://doi.org/10.1123/jsr.2018-0295.Dean CM, Richards CL, Malouin F., 2000

33. Dean CM, Richards CL, Malouin F. Task-related circuit training improves performance of locomotor tasks in chronic stroke: a randomized, controlled pilot trial. Arch Phys Med Rehabil. 2000;81:409-17. https://doi.org/10.1053/mr.2000.3839 
34. Podsiadlo D, Richardson S. The Timed "Up \& Go": a test of basic functional mobility for frail elderly persons. Clin Invest. 1991;39:142-8. https://doi.org/10.1111/j.1532-5415.1991. tb01616.x

35. Morris S, Morris ME, Iansek R. Reliability of measurements obtained with the timed "Up \& Go" test in people with Parkinson disease. Phys Ther. 2001;81:810-8. https://doi.org/10.1093/ $\mathrm{ptj} / 81.2 .810$

36. Kim WK, Lim LJ, Choi PI. The effect of stretching exercise on flexibility, balance, and duration of mental retardation in elementary school children. J Mental Retarda. 2006;8(2):157-81.

37. Giammattei J, Blix G, Marshak HH, Wollitzer AO, Pettitt DJ. Television watching and soft drink consumption: associations with obesity in 11- to 13-year-old schoolchildren. Arch Pediatr Adolesc 4 Med. 2003;157:882-6. https://doi.org/10.1001/archpedi.157.9.882

38. Hwang EO, Oh DW, Kim SY, Choi JD. Effects of community-based adaptive ambulation training on walking function in patients with post-stroke hemiparesis. Korean J Health Promot Dis Prev. 2010;10:78-85.

39. Lim BO, Kim KW.The Effects of muscle, balance and walking training on the ground reaction force of gait in children with down syndrome. Korean J Sport Sci. 2010;21:1115-22.

40. Son WI, Back JH, Lee JS, Lee YS, Song JH. The Effects of muscle strength, balance and gait training on gait pattern development in mental retarded and hearing-impaired people. Korean J Sports Sci. 2013;22:1531-46.

41. Song SH. The effects of eccentric muscle contraction program on walking and balance ability of children with brain lesion disorder. The Asian J Kinesiol. 2019;21:46-54. https://doi. org/10.15758/ajk.2019.21.1.46

42. Kim HY, Jeong SM, Kim YD. Effects of sit-to-stand movement on walking in patients with hemiplegia after a stroke. J Korean Soc Neurother. 2015;19:41-6.

43. Carlberg EB, Hadders-Alqra M. Postural dysfunction in children with cerebral palsy: some implications for therapeutic guidance. Neural Plast. 2005;12:221-8. https://doi.org/10.1155/ NP.2005.221

45. Shumway-Cook A, Brauer S, Woollacott M. Predicting the probability for falls in community-dwelling older adults using the Timed Up \& Go Test. Phys Ther. 2000;80:896-903.

46. Lee CW, Lee IS, Kim HS. The effect of horse-riding exercise on the balance ability in the frail woman elderly people.J Korean Society Integrat Med. 2013;1:59-66. https://doi.org/10.15268/ ksim.2013.1.2.059

47. Choi AY, Cho WS. The effects of mechanical horseback riding exercise on the dynamic balance in patients with cerebral infarction. J Korean Soc Phys Ther. 2014;26:123-9.

48. Studenski S, Perera S, Wallace D, Chandler JM, Duncan PW, Rooney E, et al. Physical performance measures in the clinical setting. J Am Geriatr Soc. 2003;51:314-22. https://doi. org/10.1046/j.1532-5415.2003.51104.x

49. O'sullivan SB, Schmitz TJ. Physical rehabilitation: assessment and treatment. 4th ed. Philadelphia, PA: FA Davis; 2000.

50. Ng SS, Hui-Chan CW. The timed up and go test: its reliability and association with lower-limb impairments and locomotor capacities in people with chronic stroke. Arch Phys Med Rehabil. 2005;86:1641-7. https://doi.org/10.1016/j.apmr.2005.01.011

51. Yoon ST, Park BH. The impact horse riding exercise program has on adults with intellectual disability in physical, psychology factors, social factors of disabled. Korean J Adapt Phys Act. 2013;21:81-95. https://doi.org/10.17006/kjapa.2013.21.1.81 